\title{
Study on Teaching Quality Evaluation Criteria of General Music Education Course in Colleges and Universities
}

\author{
Yongxin Ai \\ Anshan Normal University \\ Anshan, China
}

\begin{abstract}
Nowadays, the establishment of general music education course in colleges and universities is an indispensable important teaching link in higher education. The general music education is also growing vigorously in Chinese colleges and universities. But because of its special nature, a more comprehensive evaluation criteria meeting the development of China's higher education has not been formed. This paper mainly discusses from the formulation and implementation research of the teaching quality evaluation criteria of general music education course in colleges and universities, hoping to make some contribution to the good development of general music education course in the colleges and universities with Chinese characteristics.
\end{abstract}

Keywords-colleges and universities; general music education; evaluation criteria

\section{INTRODUCTION}

The overall-developed talents are more in line with the society development demand in the current era, and the corresponding education reform is also the eternal theme of human development and progress. In Chinese society, however, the deepening reform of higher education has entered into a new stage, and "general education" is recognized by more and more education workers. This kind of education mode is different from the traditional professional education, focusing on cultivating students' sound personality, good moral character and comprehensive and profound cultural background.

"General Education" is translated from English [1], and it is also translated as "Common Education", "Ordinary Education" and "All-round Education" and so on. In the early 19th century, education workers associated this educational idea with higher education for the first time [2]. More and more education workers are keen to make related studies on this education form. But so far, there is no normative statement about general education in educational circles. The author thinks that as for the definition of general education, different people have different views, and any non-professional higher education mode meeting education development can be involved in the category of "general education". And more often than not, "general education" is not only a means of education, but also a teaching philosophy, and its essence is a kind of education strategy. In the 1980s, scholars in Taiwan introduced "General Education" formally into China's higher Education, and translated it into "General Education" by referring to China's traditional culture connotation. Nowadays, China's higher education has listed general education as an important teaching mode. In fact, as early as in ancient China, there was cognition about "general education". "The Book of Changes" argues that "gentleman shall learn more about predecessor's words and previous actions"; "Doctrine of the Mean" argues that anyone who engaged in scholarship shall be "learned, questioning, careful, discernment, and practicing sincerely"; Lun Heng written by Wang Chong of Eastern Han Dynasty says that: "those who read extensively of the ancient and modern is the learned person", "those who read thousands of millions of books, carry forward "Yayan" (elegant language), examine and approve official documents and correspondence, and regard who can teach his as teacher is the learned person." These facts indicate a truth, namely, general education plays a vital role in cultivating comprehensive talents, and read widely, reasonable, and adaptable to changing circumstances may be the most understanding of "all-round talents", and shall be the ultimate goal of the school running concept of Chinese colleges and universities, as well as the educational method to promote the harmonious development of personality.

General music education mainly takes aesthetic as the core, aiming to cultivate students' good sentiment and sound personality, as well as to cultivate students' creativity. Therefore, the formulation of teaching quality evaluation criteria of general music education course in the relatively well-developed colleges and universities is of the positive and important role for promoting the development of general music education.

\section{FORMULATION OF TEACHING QUALITY EVALUATION CRITERIA OF GENERAL MUSIC EDUCATION COURSE IN COLLEGES AND UNIVERSITIES}

Currently, the general music education course is mainly set up for the students specialized in non-musical specialties in China's various colleges and universities, and most the courses mainly can be divided into such three categories as the music aesthetic appreciation, skill learning and music professional knowledge learning. From the current teaching situation, music aesthetic appreciation courses have become the main 
body of the music education course in colleges and universities because of its fixed teaching content, teaching means as well as the simple evaluation mode. The common appreciation typed music education courses focus on imparting the music history, starting from the appreciation of related musician's works to the introduction and learning of the background, a "complete set" and "perfect" teaching mode has been formed. In order to complete the teaching mission, the majority of such courses are conducted in "big classroom" with large number of students and the teaching hours are also very limited. In most cases, the single way of teachers' teaching is adopted and the reasonable effective discussion between teachers and students is impossible to be carried out, which are the limitations of such courses. The art appreciation ability is not improved substantially, let alone the enhancement of aesthetic ability. This has resulted in students' selection motivation of optional courses deviate from the teaching purpose, and the students only select the courses that are easy to obtain high points and memory, with simple evaluation method. Students take completing the credits of general course as main purpose, so they have no time to experience the role of general music education course in improving the aesthetic ability and sound personality.

It can be seen from the above that "it is necessary to have effective tools to do good work", therefore, the establishment of an effective teaching quality evaluation criteria of general music education course in colleges and universities is extremely urgent. The setting of such teaching quality evaluation criteria shall be started form such three aspects as evaluation principles, evaluation content and evaluation methods.

\section{A. Evaluation Principles}

The setting of teaching quality evaluation principles for general music education course in colleges and universities shall be started from the following four aspects:

1) Guidance principle: The teaching quality evaluation criteria of general music education course in colleges and universities shall be formulated focusing on students' overall development, and shall be conducive to promote the student's understanding of their own progress, discover and develop their own sense of music and creative ability, to further improve their individual culture quality, and to establish correct objectives for cultivating students' sense of responsibility and correct world outlook, and outlook on life and values. At the same time, it is beneficial to professional teachers in colleges and universities to summarize teaching experience, to improve their education and teaching level, and to promote music education and curriculum reform in the new period develop toward the good orientation of all-round quality education.

2) Scientific principles: The determination of evaluation purpose shall the selection of evaluation methods shall be based on the scientific principles, which cannot be created out of nothing, nor made out subjectively. It shall focus on giving play to the characteristics of music courses, and take the standards of different teaching content as reference, to reflect the characteristics of general music education course in colleges and universities. Moreover, it shall conform to the personality development characteristics of the students specialized in non-musical specialties in current colleges and universities as well as the objective requirements and law of the music aesthetic education.

3) Integrity principle: Any implementation of education can't be conducted behind closed doors. There shall be scientific views to treat the problems relating to evaluation, no matter it is set from the details of curriculum planning, audience subject, methods and ways as well as evaluation methods details, or is studied from macro system of education, which cannot be overgeneralized. Summary shall be made in different teaching stages to digest it, and carry forward the teaching advantages, correct shortcomings, to make the overall teaching process get a long-term development, playing a role of promoting the implementation of teaching quality evaluation of general music education course in colleges and universities in the future.

4) Practical principles: The methods of teaching quality evaluation on general music education course in colleges and universities shall be concise, simple and feasible, which is easy to be implemented. According to the characteristics of general music education course in colleges and universities, combine the qualitative evaluation and quantitative evaluation, as well as the formative evaluation and summative evaluation, to make the evaluation and teaching supplement each other. The realtime self-assessment and evaluation by others shall be formed in the teaching process, enabling the two combine organically, to promote the implementation of teaching contents and sound development of teaching order, to form the good, lively, vivid and orderly evaluation atmosphere, thus to establish the perfect education evaluation mechanism.

\section{B. Setting of Evaluation Content}

Excellent general music education course shall have the complete and perfect teaching content. The following aspects shall be focused on for the evaluation content reference of general music education course in colleges and universities:

1) Classical humanities education: Actually, Humanities is a general name of all the academic categories summarized by the philosophy-workers in the 20th century by excluding natural science and social sciences. In fact, Humanities mainly studies the history of human activities and the behaviors formed by the matters relating to human creativity, without clear definition distinguishing form the other two categories. But there's no doubt that art belongs to the Humanities, and the higher education of art is also belonging to the category of Humanities education, because the establishment of music vocabulary, the development of musical instruments and researches relating to the development of music are associated with human spirit's scope, depth and capacity. The "seven arts" developed from the Rome "liberal arts" in the middle ages are included in the category of Humanities, namely grammar, logic, rhetoric, arithmetic, geometry, music, and astronomy. Thus, in the definition of classical humanistic education, music belongs to the principle of studying human creativity. The content setting of general music course in contemporary colleges and universities shall adhere to the 
teaching principle of "people-oriented", and take "music creation activity" as the main teaching method.

2) Contemporary general education: Contemporary general education mainly advocate to widen students' vision, achieve higher level of self-awareness after comprehensive understanding of traditional subject knowledge, pay attention to detail research, and at the same time, the sense of general situation is required while against narrow specialization, and advocate to understand the free and scientific concept. In the United States, the ultimate goal of general music education in colleges and universities is to promote students' interdisciplinary study, improve their art culture quality, and establish a perfect personality. So the setting of genera music course in China's colleges and universities shall not just complete the pure teaching task, but it shall take the cultivation of "people" as the main purpose.

In conclusion, corresponding adjustments shall be made to the contents of general music course in colleges and universities, and the subsequent teaching evaluation content shall also be reformed. It is unilateral to set the contents of general music education course only in accordance with the professional music education evaluation content. For instance, while explaining rhythm in general music course, it cannot just introduce the definition, type, combination mode of rhythm, because as for the students specialized in non-musical specialties, intuitive feelings are more important. Students can be guided to imagine reasonably, and associate with the daily life, and make reasonable arrangements for rhythm types. Thus, it can not only deepen students' impression, but also can arouse the students' enthusiasm toward learning, at the same time, the evaluation of teaching quality can grasp more substantial data, which is also good for the setting of next teaching content. Teaching and evaluation complement each other to form good circulation.

\section{Evaluation Methods}

Generally, the following methods can be adopted as the evaluation methods of general music course in colleges and universities:

1) Non-quantitative evaluation: The non-quantitative evaluation is a kind of qualitative assessment, which refers to the course teaching quality is not described and judged by mathematical calculation, but by the ways of observation, inspection and records. The commonly used non-quantitative evaluation methods in higher education in China include ranking, comments, etc. Specifically, ranking refers to that the teaching evaluators determine the teaching implementers' teaching quality meeting which teaching level that has been planned according to the requirements of teaching evaluation index system and teaching quality management standards. Generally, there are three-level method (higher, middle and lower), four-level method (excellent, good, medium, and poor) and five-level method (excellent, good, medium, pass, fail). The defect of such evaluation method is the subjective consciousness is strong, and the rating grades have not been clearly defined. Yet the method of comments is the same as rating, which is very simple, generally it takes the cognition of course implementation as the main evaluation criteria: classroom teaching contents conform to the requirements of syllabus, highlighting the key and difficult points with proper teaching methods, and students' subject consciousness of learning is strong with good classroom teaching effect as well as basically realize the teaching goal, etc. Although the pertinent comments plays actively supporting role for teaching evaluation, it is the same with ranking method, as the evaluators' subjective consciousness is strong, which is difficult to reflect teaching quality comprehensively. Therefore, the non-quantitative evaluation can be adopted for the evaluation of relevant general music education courses, but we cannot rely on this method completely.

2) Quantitative evaluation: Relative to the non-quantitative evaluation, quantitative evaluation often adopted mathematical statistics method to evaluate the teaching activities accordingly. With the development and improvement of educational measurement, educational statistics, educational evaluation and fuzzy teaching, quantitative method has been increasing valued in the field of teaching evaluation. Generally, it is divided into classification scoring evaluation and comprehensive evaluation. Classification scoring evaluation, namely, to conduct corresponding scoring evaluation on various teaching links of the teaching implementers, and then make the integrated calculation to gain the evaluation conclusion; Comprehensive evaluation is to evaluate the overall teaching. It seems that the teaching process hasn't been broken down during the evaluation process, but in fact, the evaluators have conducted corresponding classification integration on teaching links in their mind, and the data obtained is the final result, which has certain requirements on the evaluators' experience and evaluation accuracy and the grasp of the key information of the evaluated during teaching process.

3) Third-party evaluation: The above two kinds of evaluation methods can also be applied to the evaluation on the teachers' self teaching evaluation and the evaluation on what the educated have learned. But both of the two are directly involved in the whole teaching process, the influence of subjective consciousness is inevitable, which requires the third-party to conduct the objective teaching evaluation. Third party evaluation generally refers to the evaluation on lower level school by the superior administrative department, the evaluation on teachers' teaching by school administrators, and the evaluation on school's teaching quality by social public opinion. Advantage is the evaluation is objective and comprehensive, while disadvantage is it costs large amount of time, material, and financial resources due to its severity, so such evaluation method is not fit to be carried out frequently.

Therefore, the teaching evaluation of general music course in colleges and universities shall make the best use of the circumstances, select the method that is suitable for this subject, and combine multiple methods, to inspect whether the teaching implementers' various teaching levels and the content actually accepted by the educated meet the evaluation requirements, and make comprehensive consideration, to obtain the objective and real evaluation, thus to carry out the effective teaching reform, so as to promote the healthy and comprehensive development of this discipline. 


\section{REFERENCES}

[1] The 21st Unabridged English-Chinese Dictionary, Beijing: China Renmin University Press, 2005

[2] Feng Lanfang. Twenty Years' Retrospect and Outlook of Music Education in Common Colleges and Universities (1978-1998) [J]. People's Music,1999(10).

[3] Ma Da. Music Education Development in Chinese Schools in 20th Century (Eighteenth) [J]. China Music Education, 2001(6).

[4] Dai Dingcheng. Music Education Outlook [M]. Shanghai: East China Normal University Press, 2001. 